INVESTIGACIÓN

Recibido: 10/05/2021 --- Aceptado: 13/09/2021 --- Publicado: 03/01/2022

\title{
DE LA OCUPACIÓN AL COVID, PASANDO POR LOS MENAS. EL DIÁLOGO SEMIPRESENCIAL COMO METODOLOGÍA INNOVADORA DE APRENDIZAJE ANTROPOLÓGICO
}

\section{From Occupation To Covid, Passing Through The M.E.N.A.S. Semipresential} Dialogue As An Innovative Methodology Of Anthropological Learning

María Isabel Ralero Rojas. Universidad de Castilla-La Mancha. España. $\underline{\text { mariaIsabel.Ralero@uclm.es }}$

Cómo citar el artículo:

Ralero Rojas, M-I. (2022). De la ocupación al COVID, pasando por los M.E.N.A.S. El diálogo semipresencial como metodología innovadora de aprendizaje antropológico. Vivat Academia. Revista de Comunicación, 155, 197-217. $\underline{\text { http://doi.org/10.15178/va.2022.154.e1384 }}$

\section{RESUMEN}

El método dialógico como técnica mixta de investigación y aprendizaje tiene un desarrollo muy prometedor dentro y fuera de las aulas. Ello supone asumir que el papel del alumnado puede equipararse al de los sujetos que construyen la realidad social donde se ubican nuestros objetos-sujetos de estudio, y que desde ese rol pueden convertirse en importantes fuentes de reflexividad para adentrarnos en el análisis de hechos sociales relevantes en el momento actual. Introducir en las aulas herramientas que permitan deconstruir determinadas realidades a partir de los propios discursos de las y los estudiantes, facilita en gran medida su cuestionamiento, más aún si tenemos en cuenta que estos futuros profesionales del ámbito social desempeñarán su trabajo en sociedades complejas en donde el diálogo sumergido en la diversidad puede ser clave para alcanzar una verdadera comprensión de dicha complejidad. En el contexto de crisis sanitaria actual, además, los espacios virtuales y la semipresencialidad han supuesto nuevos retos pero también nuevas oportunidades con las que enriquecer los procesos educativos. Con este trabajo comprobaremos, a través de la propia literalidad del alumnado, cómo desde un grupo de discusión semipresencial se pueden construir cuestiones clave antropológicas basadas en los propios intereses del grupo, alcanzando en una sola sesión importantes aprendizajes curriculares tanto transversales como específicos de la materia. Esto puede contribuir a entender mejor el papel docente como acompañante en esta construcción, de manera que sea posible atender a diversidad de planteamientos y posiciones existentes dentro y fuera del aula. 
De la ocupación al COVID, pasando por los M.E.N.A.S. El diálogo semipresencial como metodología innovadora de aprendizaje antropológico

PALABRAS CLAVE: grupos de discusión- aprendizaje dialógico- investigación cualitativa - docencia antropológica - semipresencialidad - virtualidad - ocupación Covid - menas (menores extranjeros no acompañados).

\begin{abstract}
The dialogical method as a mixed technique of anthropological research and learning can have a very promising development inside and outside the classroom. This implies assuming that the role of the students can be equated with that of the subjects who construct the social reality where our objects-subjects of study are located, and that from this role they can become important sources of reflexivity to delve into the analysis of relevant social facts. in the present moment. Introducing tools in classrooms that allow deconstructing certain realities based on the students' own discourses greatly facilitates their questioning, even more so if we take into account that these future professionals in the social field will carry out their work in complex societies where dialogue seems fundamental to reach a true understanding of this complexity. In the context of the current health crisis, in addition, virtual spaces and blendedness have brought new challenges but also new opportunities with which to enrich learning processes. With this work we will be able to see, through the students' own literality, how through a blended discussion group it is possible to construct key anthropological questions based on the group's own interests, reaching in a single session important transversal and specific curricular learning of the mattery. This can contribute to a better understanding of the teaching role as companions in this construction, so that it is possible to attend to the diversity of approaches and positions existing inside and outside the classroom.
\end{abstract}

KEYWORDS: discussion groups - dialogic learning - qualitative research anthropological teaching - blendedness - virtuality - occupation - Covid unaccompanied foreign minors.

\title{
DA OCUPAÇÃO À COVID, PASSANDO PELAS MENAS. DIÁLOGO SEMIPRESENCIAL COMO METODOLOGIA INOVADORA DE APRENDIZAGEM ANTROPOLÓGICA
}

\section{RESUMO}

O método dialógico como técnica mista de pesquisa e aprendizagem tem um desenvolvimento muito promissor dentro e fora da sala de aula. Isso implica assumir que o papel dos alunos pode ser equiparado ao dos sujeitos que constroem a realidade social onde nossos objetos-sujeitos de estudo estão localizados, e que a partir desse papel eles podem se tornar importantes fontes de reflexividade para aprofundar a análise de fatos sociais relevantes.A introdução de ferramentas nas salas de aula que permitam desconstruir certas realidades dos discursos dos próprios alunos facilita muito seus questionamentos, ainda mais se levarmos em conta que 
De la ocupación al COVID, pasando por los M.E.N.A.S. El diálogo semipresencial como metodología innovadora de aprendizaje antropológico

esses futuros profissionais da área social farão seu trabalho em sociedades complexas onde o diálogo imerso na diversidade pode ser a chave para alcançar uma verdadeira compreensão desta complexidade. Além disso, no contexto da atual crise de saúde, os espaços virtuais e a integração trouxeram novos desafios, mas também novas oportunidades para enriquecer os processos educativos. Com este trabalho verificaremos, através da própria literalidade dos alunos, como a partir de um grupo de discussão misto é possível construir questões antropológicas fundamentais a partir dos próprios interesses do grupo, alcançando em uma única sessão importantes aprendizagens curriculares, transversais e específicas aos assuntos. Isso pode contribuir para uma melhor compreensão do papel do professor como companheiro dessa construção, de modo que seja possível atender à diversidade de abordagens e posicionamentos existentes dentro e fora da sala de aula.

PALAVRAS-CHAVE: grupos de discussão - aprendizagem dialógica - pesquisa qualitativa - ensino antropológico - blendedness - virtualidade - ocupação - Covid menas (menores estrangeiros não acompanhados).

\section{INTRODUCCIÓN}

El Covid ha irrumpido en las aulas con algunos cambios y medidas para garantizar la salud de docentes y alumnado, que en principio han podido provocar un desajuste importante en cuanto a las programaciones didácticas y la metodología con la que alcanzar los objetivos curriculares. También ha supuesto un mayor uso de la virtualidad como espacio de aprendizaje y una adaptación de contenidos al uso de estas herramientas. Este nuevo contexto del entorno educativo, en donde la semipresencialidad ${ }^{1}$ además genera importantes retos para avanzar no únicamente en la exposición de contenidos por parte del profesorado, sino también en la participación del alumnado en sus propios procesos educativos, nos ha permitido en cambio reflexionar sobre la manera de conectar lo de fuera con lo de dentro. Lo que pasa dentro del aula, con lo que sucede más allá del entorno clásico de aprendizaje.

Y este nuevo marco reflexivo nos posibilita explorar nuevas fórmulas educativas que supongan importantes cambios de roles en el proceso de construcción de conocimiento. Podríamos en cambio pensar desde estos planteamientos impuestos por la situación sanitaria, que en cierta medida alejan al alumnado, que ahora es menos probable que antes encaminarse hacia un aprendizaje dialógico de cualquier materia. En este sentido, la Teoría del Aprendizaje Dialógico (Flecha, 1997) nos aclara que el aprendizaje depende de las interacciones y no tanto de procesos generados desde la individualidad, por lo que tenemos en nuestras aulas la herramienta más importante para garantizar la calidad educativa: el propio grupo. Así, si el grupo es dividido en dos contextos diferentes, el presencial y el no presencial, debemos intentar

\footnotetext{
1 Vamos a definir este concepto como un espacio mixto de trabajo, que combina momentos presenciales en el aula con otros donde la participación en actividades dialógicas educativas se produce desde casa.
} 
De la ocupación al COVID, pasando por los M.E.N.A.S. El diálogo semipresencial como metodología innovadora de aprendizaje antropológico

conjugar ambos de la forma más productiva posible: a través de la asignación de diferentes roles en la construcción de conocimiento colectivo. Desde este marco además, los conceptos de acción instrumental y de acción comunicativa son útiles para identificar dos tipos de relaciones que tienen un papel fundamental en educación, las de poder y las dialógicas (Duque y Prieto, 2009: 11), en donde las herramientas participativas basadas en el diálogo suponen la aplicación de una lógica más igualitaria de conexión de diferentes posiciones en donde el aprendizaje puede hacerse más diverso y más efectivo.

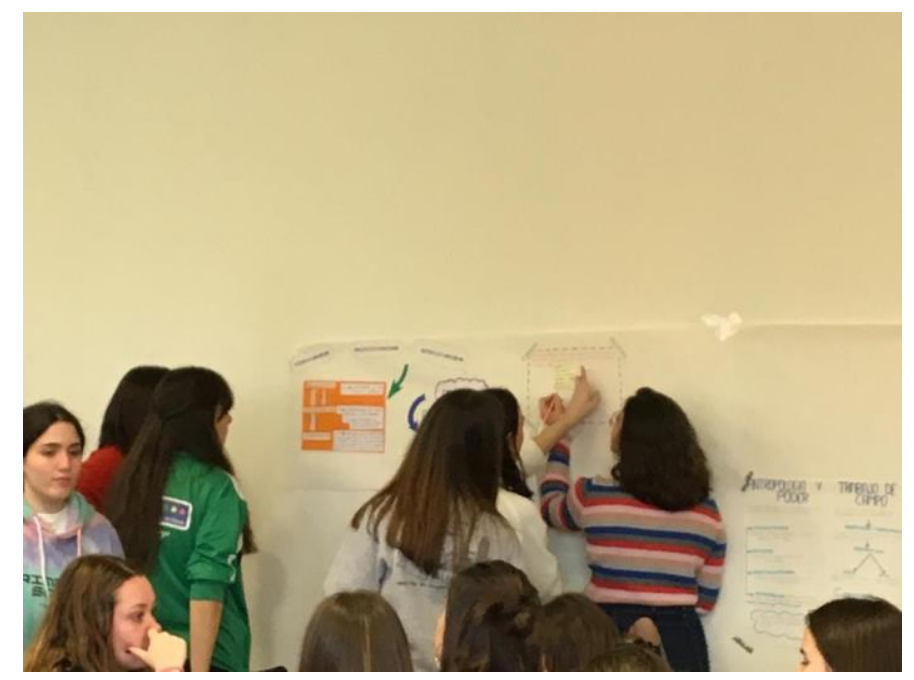

Imagen 1. Construcción dialógica presencial de conceptos antropológicos en Grado de Trabajo Social. Curso 2019-2020 (primer cuatrimestre).

Este trabajo pretende reflexionar sobre ambas relaciones en este nuevo entorno de semi-presencialidad que aparece en el curso 2020-21, desde el análisis de un proceso de aprendizaje concreto llevado a cabo a través de la técnica del grupo de discusión, observando cómo conectando este nuevo contexto con algunos contenidos antropológicos fundamentales para la comprensión vehicular de la asignatura, dichos contextos pueden transformarse en factores clave para el aprendizaje. Esto se entiende desde el ejercicio didáctico de una Antropología dialógica-crítica, en donde se aprecia una posición más activa de los actores sociales en la investigación y la producción del conocimiento no es unilateral, sino en colaboración (Hernández Espinosa, 2007: 321). Ello puede contener una fuerte dimensión aplicada, puesto que, si concluimos que la dialéctica establecida permite el flujo de ideas y pensamientos, posibilitando cambios o mejoras en dichas percepciones, se podrían plantear propuestas que empleen estas técnicas dialógicas como metodología sensibilizadora y de transformación social con los propios colectivos implicados. Esto puede cobrar especial relevancia si tenemos en cuenta la relación de herramientas basadas en la IAP (Investigación Acción Participativa) como metodologías etnográficas que nos proporcionan una oportunidad epistemológicamente superior a la investigación convencional, puesto que su acción colaborativa reúne vidas enteras de conocimientos locales y profesionales (Greenwood, 2000:47) y construyen una profundidad de lo aprendido superior a la realizada desde un enfoque más centrado 
De la ocupación al COVID, pasando por los M.E.N.A.S. El diálogo semipresencial como metodología innovadora de aprendizaje antropológico

en el investigador como posición de poder que limita e impone su propio orden científico-conceptual.

Es importante también definir conceptualmente el diálogo semipresencial como un encuentro con el otro -aquel con el que no se comparte un mismo espacio físico presencial- que permite una construcción creativa de conocimiento. Comunicación dialógica donde también se produce diálogo intercultural y que capacita en un entorno más a los participantes para el encuentro y diálogo con el otro esté donde esté, permitiendo esta relación dialogada nos conduzca al reconocimiento del carácter incompleto y finito de nuestras comprensiones culturales del mundo. Por ello, no habrá diálogo intercultural si no hay primero un distanciamiento crítico de la visión particular sobre la propia cultura: la autorreflexión de lo propio como punto de partida para la apreciación de lo ajeno (Uribe Sánchez, 2014).

Para llevar a cabo este análisis que combina metodológicamente el grupo de discusión, el aprendizaje dialéctico y la Investigación Acción Participativa, emplearemos los discursos generados en una clase de Antropología de primero de Trabajo Social de la Facultad de Ciencias Sociales de Talavera de la Reina de la UCLM, mediante un grupo de discusión compuesto por dos entornos: uno en el aula y otro desde casa. El del aula fue elegido libremente por 8 alumnas/os participantes, dos facilitadoras, y dos relatoras de conclusiones, adoptando el resto del alumnado presente un rol de observadores externos con opción a intervenir puntualmente durante el desarrollo de la dinámica, y especialmente a proporcionar su mirada tras su finalización, al día siguiente. La parte del alumnado que se encontraba desde casa seguía la clase a través de la plataforma Teams, facilitando su participación en el grupo a través del chat escrito. El rol docente en este caso sólo se ejerció desde la facilitación de la información que se generaba cuando fallaba la conexión o comprensión en ambos espacios, el virtual y presencial. Así, se ocupó de trasladar a este foro las temáticas y algunos discursos expresados en el grupo presencial, de manera que se aseguraran diferentes formas de construir opiniones entre el alumnado presente en el aula y aquellos que seguían la clase desde fuera. La dinámica de funcionamiento del grupo fue abierta. Se propusieron tres temas a elegir: la ocupación de viviendas, el debate social y político generado en torno a los menores extranjeros no acompañados y por último, el impacto social del Covid-19. Tras hacer recuento de personas a favor de cada temática, una alumna de la modalidad presencial advirtió que con el tercero se podían tratar todos, puesto que en este contexto se habían agudizado estas cuestiones. El grupo -presencial, porque el no presencial no tomó partido en esta decisión-, estuvo de acuerdo entonces en comenzar el debate de forma amplia intentando tratarlo todo si fuera posible. De esta forma, se permitía que los intereses del alumnado fueran dando forma y tiempos diversos a las temáticas propuestas.

\section{OBJETIVOS}


De la ocupación al COVID, pasando por los M.E.N.A.S. El diálogo semipresencial como metodología innovadora de aprendizaje antropológico

- Comprobar la capacidad adaptativa del método dialógico a través del desarrollo de un grupo de discusión semipresencial, cuando los objetivos de los aprendizajes curriculares son integrados en la diversa funcionalidad de ambos grupos.

- Desarrollar el análisis discursivo generado por el propio grupo en el aula mediante el uso participativo de un entorno mixto presencial y virtual, observando la conexión entre conocimientos, valores y percepciones previos del alumnado y la complejidad sociocultural existente en las realidades actuales.

- Analizar la efectividad del aprendizaje construido diversa y colectivamente para materias antropológicas que requieren de una fuerte reflexividad.

Con estos objetivos podremos valorar hasta qué punto el diálogo semipresencial generado con dos grupos diferenciados (presencial en el aula y no presencial desde casa) puede ser útil para la construcción antropológica de conocimiento, sobre todo desde su perspectiva EMIC (mirada interna del propio grupo) y ETIC (mirada externa). También, si bajo esta modalidad sigue siendo posible y/o deseable la aplicación de didácticas participativas dialógicas y, finalmente, si lo observado en el desarrollo de este análisis concreto pudiera ser de utilidad para avanzar más hacia la construcción dialogada de nuevas metodologías docentes innovadoras de investigación -acción semipresenciales, que sin duda permitirían una mayor implicación de actores sociales en procesos de transformación social.

\section{METODOLOGÍA: LOS GRUPOS DE DISCUSIÓN COMO HERRAMIENTAS DE CONSTRUCCIÓN DE CONOCIMIENTO}

A pesar de que existen diversas formas de concebir y materializar un grupo de discusión dependiendo de la disciplina y/o profesionales que lo pongan en práctica, vamos a partir de una definición amplia que nos permita poner el foco en el diálogo generado por encima de sus pautas de aplicación. Al movernos en este caso por una experiencia construida y analizada desde la didáctica antropológica, nos interesa especialmente la acción del alumnado de construir su propio discurso a partir de lo que dice otro sujeto que se encuentra dentro o fuera del aula, y por lo tanto, compartiendo o no diferentes contextos de participación. Así, sea de una manera u otra, la confrontación de puntos de vista entre los participantes en un grupo de discusión permite a éstos formar y concretar sus posturas o evolucionar en sus planteamientos (Gil, 1993: 210), haciendo posible que en ese espacio mixto constituido por la semipresencialidad se construyan sentidos y significados, compartidos y no compartidos. De esta forma, a través de la conversación socializada, del habla y la reflexión, se encontraron el sentido y la significación del tema y se construyeron y legitimaron los universos simbólicos o imaginarios sociales (Arboleda, 2008: 72).

Si bien los grupos de discusión constituyen una técnica cualitativa muy empleada desde ámbitos como la Sociología y la Antropología Social, la discusión o el diálogo nos ayuda a obtener información significativa sobre ese universo simbólico que hace 
De la ocupación al COVID, pasando por los M.E.N.A.S. El diálogo semipresencial como metodología innovadora de aprendizaje antropológico

que "las personas piensen o sientan en la manera en que lo hacen" (Krueger, 1991: 22, citado por Porto y Ruiz, 2014: 253). Entendemos entonces el grupo de discusión como una técnica/práctica cualitativa de la que se obtiene una materia prima discursiva, cuyo análisis servirá para dar cuenta de las representaciones e imágenes colectivas, así como las estructuras grupales que se articulan en torno un significante o/y determinada problemática objeto de estudio (Montañez, 2010: 2). Esta técnica permite establecer un diálogo, en este caso entre el alumnado participante, a la vez que se construye un discurso grupal, rico en códigos, expresiones, opiniones y silencios, que permita un despliegue de hablas y voces, y genere un estímulo para la creación de sentidos y significados (López Francés, 2010: 148).

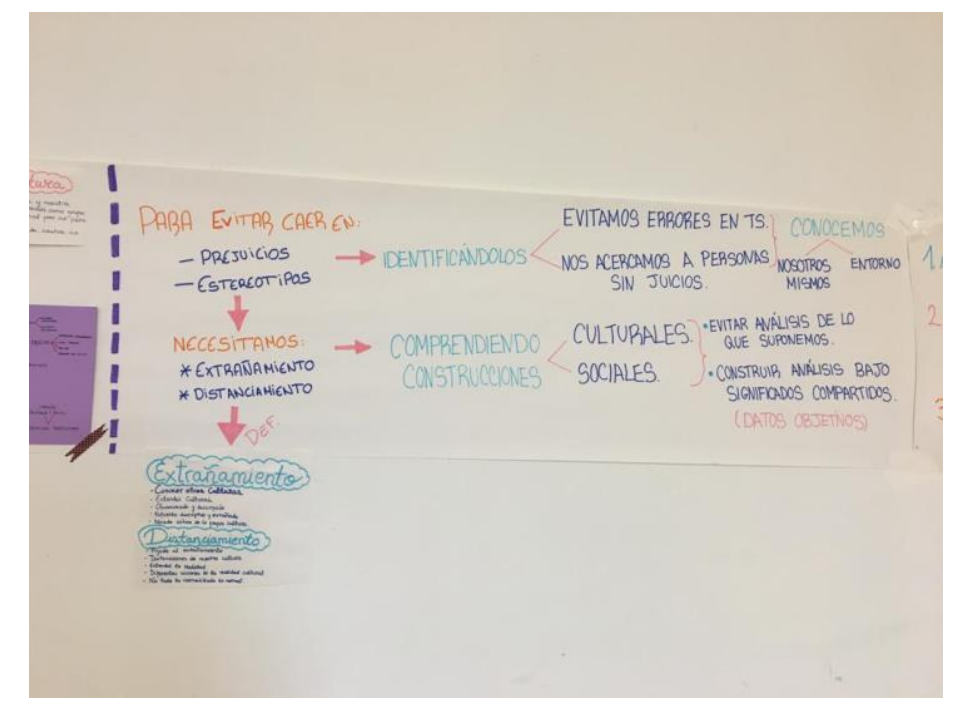

Imagen 2. Esquemas realizados de forma dialógica por el alumnado presencial sobre concepto de extrañamiento y distanciamiento cultural.

Esta consideración del grupo de discusión como herramienta de aprendizaje dialógica, a la vez que instrumento de investigación cualitativa que permite accedera esas representaciones colectivas significativas para el contexto actual, nos invita a reflexionar sobre su uso y vinculación con nuevas fórmulas educativas como la semipresencialidad mediante el uso de plataformas virtuales. Ello nos sugiere nuevas vías exploratorias para el aprendizaje mixto -entre lo presencial y lo virtual-, si modificamos el papel del alumnado desdela recepción pasiva a la construcción activa de contenidos vinculados con sus percepciones sobre el propio contexto social vivido.

Esta experiencia debe contextualizarse además dentro de un aprendizaje colaborativo/cooperativo mediado por ordenador referido al aprendizaje en línea, capacitado para valerse de las distintas modalidades -presencial, no presencial y semipresencial- y que usa como método de enseñanza, el aprendizaje cooperativo y/o colaborativo (Salmerón, Rodríguez, y Gutiérrez, 2010: 165). Desde la construcción dialógica de este conocimiento social, observamos el propio método como posibilidad de investigación (Muñoz, 2013: 2), con implicaciones 
De la ocupación al COVID, pasando por los M.E.N.A.S. El diálogo semipresencial como metodología innovadora de aprendizaje antropológico

interdisciplinares en otros muchos campos necesarios para la dimensión holística de la Antropología.

En el contexto específico de la enseñanza formal de una materia como la Antropología Social y Cultural, es importante que se atienda al propio conocimiento y experiencia del alumnado comosujeto representativo de las imágenes predominantes en diferentes contextos socioculturales: jóvenes procedentes de ámbitos rurales, urbanos, de migraciones internas o internacionales, pertenecientes a mayorías o a diferentes minorías étnicas o religiosas. Personas atravesadas como todas por roles de género, de edad, de clase social. Portadores de prejuicios y estereotipos propios y ajenos. De identidades colectivas o sentidos de pertenencia particulares y compartidos. Usuarios, participantes, ciudadanas/os de un mundo globalizado. Votantes y simpatizantes. Vecindad. Futuros trabajadores del ámbito público y/o privado. Con esa diversidad existente en el aula, se hace inevitable contar con ella para la reflexión colectiva de todas esas grandes temáticas antropológicas: contamos dentro de nuestro grupo con aprendices con una cantidad importante de posiciones, significados y categorías vividas en primera persona desde las cuales partir, ejercitando el extrañamiento propio y ajeno, para llegar a comprender la complejidad de nuestras sociedades actuales. Y este lugar privilegiado se multiplica si se pone en relación con la construcción de aprendizajes dialógicos.

\section{RESULTADOS. LA VALIDEZ DEL DIÁLOGO SEMIPRESENCIAL PARA LA CONSTRUCCIÓN DE CONOCIMIENTO ANTROPOLÓGICO}

\subsection{Lo dialógico como fuente etnográfica desde donde construir lo inesperado}

En muchas ocasiones, los aspectos más relevantes de nuestros trabajos de campo antropológicos aparecen en las conversaciones informales o encuentros inesperados. Así, igual que asumimos que la calidad de nuestras investigaciones no depende tanto de nuestro propio trabajo individual intelectual como de nuestra capacidad para interactuar y despertar reflexividades junto con los sujetos que interactuamos, debemos pensar que algo similar ocurre cuando nos hallamos en un espacio educativo en donde nuestro rol es el de facilitar el acceso al conocimiento -en el caso que nos ocupa también antropológico-. Esto supone admitir que en el ámbito docente no sólo lo trasmitimos, también lo construimos en relación a nuestra vinculación con el alumnado. De esta manera, a través de un diálogo entre iguales que nos permita partir de sus propias percepciones e imágenes sobre ciertos temas relevantes para el análisis socioantropológico de la realidad actual, se puede avanzar hacia la adquisición de aprendizajes compartidos que nos permita pasar del ámbito de las representaciones sociales con las que contamos en el aula, al análisis del temario y la consecución de los objetivos curriculares. 


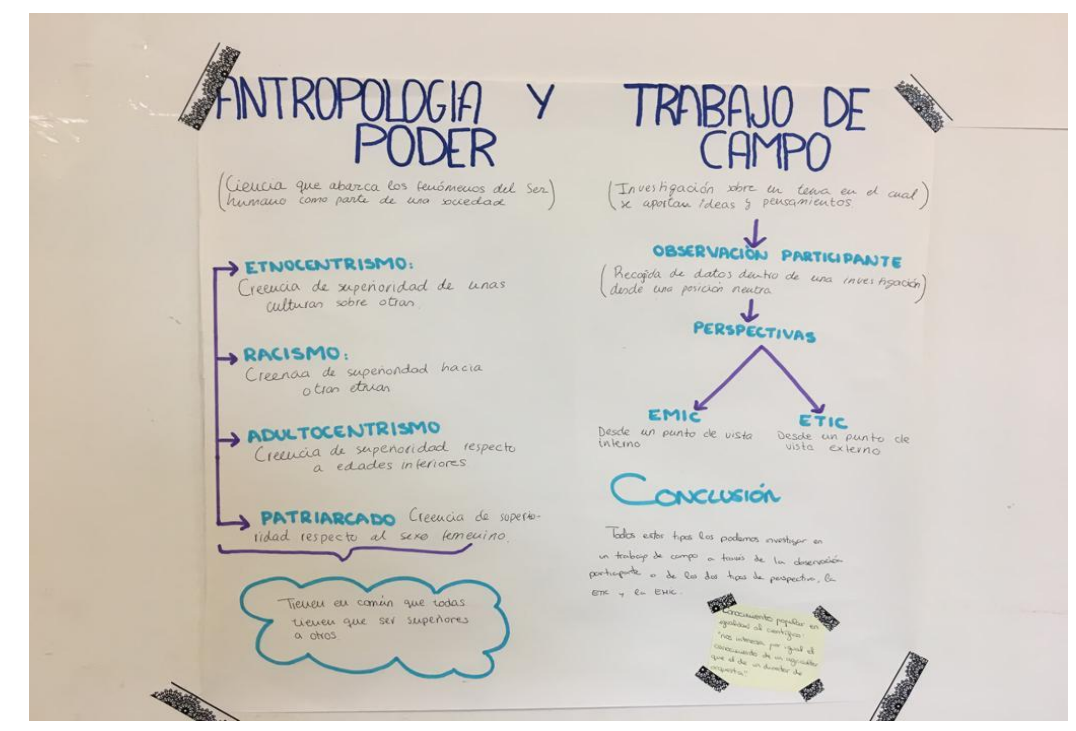

Imagen 3. Construcción dialéctica de terminología antropología en modalidad presencial.

Desde esta posición, nos sirve de la misma manera el grupo de discusión que el debate, el trabajo investigador por grupos cooperativos que las preguntas generadoras lanzadas en medio de una clase. Lo importante reside en la búsqueda del conocimiento grupal hacia un aprendizaje por descubrir tras diferentes aportaciones colectivas producidas en el aula. En ese sentido, a pesar de los cambios que haya podido generar la crisis sanitaria en las formas de relación o en la irrupción generalizada de entornos virtuales, podemos pensar que lo importante será no perdernos en esas formas, sino avanzar en mantener o mejorar a través de ellas nuestros objetivos. Ello implica tener que integrar en el ya amplio mundo de las relaciones humanas un contexto más desde donde continuar avanzando para la construcción colectiva de conocimiento. Hacerlo puede suponer un interesante reto que conlleve respuestas innovadoras.

En el trabajo que nos ocupa, vamos a describir un proceso concreto a través de la construcción grupal para posteriormente extraer algunas conclusiones importantes sobre la manera de integrar dialógicamente en los entornos educativos conceptos como semipresencialidad, virtualidad, análisis socioantropológico de categorías clave como clase social, individualidad o colectividad, marginalidad y desigualdad, procesos de exclusión social y diversidad.

\subsection{Desarrollo de la discusión: aprendizaje dialógico y construcción del conocimiento antropológico}

La discusión comenzó con el tema de la ocupación, lanzada por parte de un alumno que se posicionó "a favor", marcando de partida cierto posicionamiento ético en los discursos. Los y las participantes comenzaron a debatir sobre la legitimidad del acto en sí, intentando definir la responsabilidad social de la ocupación: si es una 
Ralero Rojas, M-I.

De la ocupación al COVID, pasando por los M.E.N.A.S. El diálogo semipresencial como metodología innovadora de aprendizaje antropológico

cuestión pública o privada, si se tiene que abordar desde la individualidad de cada caso o con una perspectiva más amplia que el grupo definió como social y por lo tanto, si requería de cierta normatividad o regulación colectiva. Desde esta consideración como un hecho social, en cambio, se llegó a la necesidad de atender a las características particulares de cada situación de ocupación, al marco legal y administrativo en donde se puede definir como delito y a cómo su simplificación permite que sea usado políticamente para legitimar los propios mecanismos de desigualdad. En cualquier caso, se generó bastante consenso en ubicar la ocupación como una práctica que surge por la falta de respuesta del estado ante la falta de vivienda, a pesar de que esta necesidad se definió también como un derecho básico fundamental:

C: "Si el estado fuera correcto no habría ocupación (...) no es una persona que invade una casa, es una familia (...) Si es una persona que literalmente no tiene nada... También se pueden generar gremios [quiere decir guetos] y la extrema derecha lo utiliza luego para decir que son esto o son lo otro (...) Y luego también hay que ser realista... ¿Quién decide que se desocupe una casa? Un juez, no es Pedro Sánchez".

Posteriormente, en la discusión se comenzó un debate interesante donde se asignaban diferentes posiciones al hecho de ocupar: como un acto consecuencia de la carencia de los medios necesarios para poder acceder a una vivienda normalizada o como un acto delictivo protagonizado por redes ilegales en donde el ocupa pasa a una posición de víctima. En cualquier caso, tras cierto debate en cuanto a estas dos situaciones definitorias, se tendió a vincular más claramente el concepto de necesidad al de ocupación. Pero al hacerlo, efectivamente salieron a escena otros actores que se benefician de esa situación desde posiciones más claramente ilegales e inmorales, y que finalmente para el grupo estarían provocando una simplificación de ideas en el imaginario colectivo y una asociación directa entre actividad delictiva y ocupación. La manera en la que se produjo esta dialéctica dialogada aporta muchas claves eneste sentido, introduciendo esas figuras intermediarias ilegales (las mafias), junto a la falta de una legislación clara y eficaz que defina mejor el concepto de necesidad atendiendo a variables como la urgencia y la escasez de medios existentes para dar respuestas:

A [desde casa]: "Estoy de acuerdo, las personas que ocupan es por necesidad, excepto en las mafias que se benefician de las personas en necesidad. Pero de nuevo este problema es de que no hay unalegislación clara y correcta sobre la ocupación y de esas lagunas legales se benefician las mafias y se perjudican los verdaderamente necesitados"

B: "No me parece justo centrar el punto ahí, eso no es lo más importante. Se criminaliza a las personas que ocupan cuando se trata de una necesidad"

F: "Pero en ese caso a cualquier persona que no le alcance el alquiler de una vivienda estaría en necesidad. Pero esa necesidad puede o no puede ser "urgente". Y no hay ayudas para todos. 
De la ocupación al COVID, pasando por los M.E.N.A.S. El diálogo semipresencial como metodología innovadora de aprendizaje antropológico

Continuó la discusión introduciendo componentes clave que pueden llegar a definir el fenómeno: la clase social y su posible relación con los barrios o zonas más vulnerables o desfavorecidas. Según fue indicando el alumnado participante, parece que determinadas prácticas podrían transitar más fácilmente por unos espacios que por otros, y que determinados prejuicios operan en la opinión pública para generar cierta confusión entre conceptos que sin ser lo mismo ni tener las mismas consideraciones legales, cumplen una importante función en las creencias colectivas que convierten la ocupación en una posibilidad a temer por cualquiera. Especialmente interesante resultó la aportación de una alumna (B) sobre los procesos simbólicos de identificación de determinados barrios con prácticas delictivas, y cómo ello puede estar incidiendo en la conformación de imágenes que favorecen la ocupación:

$\mathrm{D}$ [alumna desde casa]: "A ver, hay que hacer una diferencia de conceptos, si te "ocupan" tu vivienda habitual o tu segunda residencia, no es una okupación, es un allanamiento de morada y ahí la policía puede entrar inmediatamente sin autorización judicial, la okupación es en aquellas viviendas que no se habita en prácticamente ningún momento del año, y de esas prácticas son las menos habituales, la tele quiere hacernos confundir entre estos dos términos. Ahora hay que pensar quién se puede permitir mantener tres viviendas en este sistema económico..."

B: "Cuando tú vas a otro barrio a buscar trabajo... Los más adinerados te preguntan que si no te roban en el tuyo, te juzgan por proceder de otro barrio (...) Luego es que si te echan de una casa no lo decide el estado, el que lo decide es un juez... A lo mejor las personas ocupan casas de otras personas en barrios desfavorecidos porque quizás les resulte más fácil, o porque la mafia se lo pone más fácil alli"

A través de la participación del alumnado desde casa se fueron sumando consideraciones importantes no presentes en el debate presencial, en cuyo grupo se mostraba bastante homogeneidad en los planteamientos. Por ejemplo, de qué forma definimos la ocupación (introducido por alumna D), hasta qué punto se ha visto amplificada en este contexto Covid como agravante de la desigualdad social y si la forma de solucionar la falta de vivienda se debe producir al margen del sistema, con soluciones transgresoras que, según se expresó, tampoco permiten que las situaciones de desigualdad se modifiquen. Estas apreciaciones que se generaron desde casa, resultaron importantes para el análisis global del fenómeno, puesto que, aunque de forma mayoritaria, se llegó a observar como algo legítimo que "una familia sin opciones de acceso a una vivienda normalizada ocupe", no se quiso perder de vista que ubicar a dicha familia fuera del sistema tiene sus repercusiones y puede agravar su situación de vulnerabilidad. Al mismo tiempo, se expuso la diferencia entre la ocupación a viviendas de bancos y de particulares, así como los usos diferentes de las mismas -si es un modo de vida, un hogar, un bien económico o un lugar de residencia-, particularidades o matices que son importantes a la hora de diferenciar aquello que en cambio se nos muestra desde las narrativas del poder como una realidad homogénea y distorsionada, desde el miedo de clase media a ser ocupado y que sus esfuerzos de promoción económica a través del entramado social se vean mermados: 
Ralero Rojas, M-I.

De la ocupación al COVID, pasando por los M.E.N.A.S. El diálogo semipresencial como metodología innovadora de aprendizaje antropológico

G [desde casa]: "En mi opinión, yo no estoy de acuerdo con la ocupación de viviendas porque no se puede cambiar una situación de sistema, no se puede cambiar la estructura sin conocer los daños que ella provoca, si empezamos expulsándolos del sistema no conseguiremos una visión material del problema. Ahora bien, una familia que se ha quedado sin vivienda por los problemas socioeconómicos y que por esa vía entiende los problemas que surgen tiene derecho a ocupar una vivienda sea de una entidad bancaria o sea de un propietario particular que sea dueño de los medios de producción porque son los que provocan que haya desigualdad entre clases sociales, pero de ninguna manera hay que luchar contra el sistema ocupando viviendas sin conocer sus antagonismos"

F [desde casa]: "Para mi la ocupación es más propensa en "pequeños empresarios" ya que comienzan a cobrar la misma cantidad de impuestos a personas que apenas están emprendiendo. Poniéndolo en mi caso; si yo consigo un piso extra con ahorros y esfuerzo a lo largo del tiempo, y venga alguien que lo ocupe... me molestaría. Teniendo en cuenta que ese piso iba a ser mi sustento".

Desde el chat compartido en la plataforma para el alumnado no presencial siguieron incorporando algunos elementos importantes para el debate, como la falta de recursos públicos y la posible reconversión del excedente procedente de la burbuja inmobiliaria -en manos de los bancos-, a vivienda pública mediante la compra por parte del estado (nótese la normalización de la lógica capitalista en el alumno L), aumentando la polarización social entre ricos y pobres:

L [desde casa]: "Yo creo que el problema es del estado, que no pone suficiente dinero ni legislaciones, hay multitud de viviendas del banco que el estado podría comprar y ofrecer a la población como viviendas de protección oficial a un bajo precio de alquiler para que fuera posible que todos tuvieran un hogar propio. Hay muy pocas viviendas de protección oficial y las que hay cada vez suben más el alquiler, al estado no le interesa perjudicar a los bancos ya que la sociedad es de base capitalista y necesita de los bancos".

F [desde casa]: "Pues me he quedado en blanco. Es que es lo que hablamos también en la clase de Sociología. Personas que antes se podían permitir un piso de alquiler de 300 euros ahora ya no pueden... Porque precisamente está subiendo esa franja. Los ricos se están haciendo más ricos, y los de clase media están llegando a ser pobres".

Después de haber alcanzado cierto consenso sobre el fenómeno de la ocupación, el grupo presencial fue dando por agotado el tema y comenzó a ampliar el análisis hacia otras estructuras de desigualdad social, introduciendo el tema de los menores no acompañados y la necesidad de más apoyos a todos estos colectivos para que puedan resolver situaciones complejas. Parte del alumnado remarcó el aumento actual de los procesos de incitación al odio hacia ciertos colectivos en situación clara de desventaja social, asícomo una mayor permisividad actual hacia estas lógicas. En algunos casos, se observó cómo en un contexto de crisis socio-sanitaria, la competitividad aumenta y con ello la necesidad de culpar al "otro", bien se trate de un 
Ralero Rojas, M-I.

De la ocupación al COVID, pasando por los M.E.N.A.S. El diálogo semipresencial como metodología innovadora de aprendizaje antropológico

осира, un extranjero o un mena, generándose en torno a dichas categorías mecanismos o narrativas que excluyen y legitiman las posiciones de desigualdad:

H: "A mi me da igual si me robas que seas de España, de Ecuador (...) Pero si hay ya una mirada social negativa sobre ese tipo de personas que antes no era tanto (... ). Se va incitando al odio cada vez más... Se permite que sigan saliendo neonazis de caza... Que tú tengas la cara de acusar por ocupar un piso... porque es la salida que he encontrado... Y te creas más que otro porque no has tenido que ocupar nunca...".

B: "Quizás el estado puede hacer más... no dejar los problemas de lado (...) Si se ve como algo malo.... y hace falta más comprensión. Quizás haya que fijarse más en la mirada de lo social más que en otra cosa: madre mía los menas qué malos que son... Eso está dirigido y vemos lo que quieren que veamos".

También en el grupo presencial se hicieron eco de algunos discursos que cuestionan las elecciones o prioridades de algunos colectivos que ocupan posiciones de desigualdad social pero donde el entorno comunitario percibe sus prácticas como inapropiadas para el supuesto lugar de carencia que ocupan. En este sentido, apareció la importancia que puede tener en dichas decisiones la presión social que otorga prestigio o estatus al hecho de formar parte de determinadas prácticas, y como esas lógicas conviven con otras basadas en lo que se considera apropiado según las posiciones de desigualdad:

$\mathrm{N}$ : "El problema es que domina la economía mucho antes que lo social (...) Y a veces las prioridades que la gente elige, no ayuda... Porque lo que hacen no se entiende en un momento de crisis... Pueden llevar ropa de marca y luego piden en Caritas, lo veo en mi pueblo (...)".

K: "También es una cuestión de prioridades, pero quizás no nos lo podemos permitir económicamente... Y te ves obligado por el qué dirán (...). Es que hoy si no tienes ciertas cosas no eres nadie. No somos capaces de entender a los demás, sus razones. Tenemos que empezar cambiando nosotros para cambiar todo lo demás"

Después de valorar la importancia simbólica que estas cuestiones pueden tener para la construcción sociocultural de la diferencia, el alumnado presencial centró su análisis en lo individual y lo colectivo, observando la necesidad de contar con miradas más comunitarias y procesuales que atiendan a todas las dimensiones que entran en juego en los procesos de desigualdad y exclusión social. Así, el grupo comenzó a definir posibles estrategias con las que hacer frente a dichos procesos, analizando si los enfoques deben ser individuales o colectivos, y cómo desde dichos enfoques en la intervención se podrían proporcionar respuestas más o menos integrales u holísticas :

K: "Muchas veces yo misma, trabajando en un albergue, me encuentro gente por la calle... No nos damos la opción de mirar por los demás (...). ¿Tu red de apoyo dónde está? ¿Cómo puedo ayudar a mi vecina? Si no conozco lo que hay, no puedo ayudar. Si no puedo saber lo que te pasa y qué tienes a tu alcance para mejorar... [nota

Vivat Academia. Revista de Comunicación. 2022, n 155, 197-217 
Ralero Rojas, M-I.

De la ocupación al COVID, pasando por los M.E.N.A.S. El diálogo semipresencial como metodología innovadora de aprendizaje antropológico

profesora: ha incidido en la importancia de conocer los recursos existentes en la comunidad para poder aconsejar en su uso]"

[Nota de profesora. En este momento, algunos miembros del grupo comienzan a hacer preguntas concretas dirigidas a una participante, para saber cómo lo haría ella. Parece que cuenta con cierta consideración para la clase. Para J el problema es "la sociedad tan individualista"]:

J: "Si nos centramos en la educación para resolver la desigualdad... tendríamos que idear algo que supere la ayuda a una sola persona, al individuo, porque las respuestas individuales no resuelven realmente los problemas sociales... No sé cómo, esto hay que pensarlo mejor, pero estoy convencida de que si el problema es el individualismo, con respuestas individuales no lo vamos a resolver (...) Me parece super importante no basarnos en cosas personales... Si me baso en lo que a mi me parecen las cosas... Plantearlo como experiencias personales me sigue llegando como algo individual... Buscar una solución social no implica que basemos nuestras actuaciones por nuestros propios intereses personales..."

A partir de este planteamiento basado en la interacción entre lo individual y lo colectivo, se incluyó en el análisis la forma en la que los modelos educativos o familiares pueden o no reproducir la desigualdad social de determinados grupos. De esta forma, el diálogo generado en el grupo presencial tendió hacia una posición compartida y predominante en donde se relativizaron las creencias y conocimientos, las posiciones y las prácticas sociales según el contexto en donde se hayan generado los principales aprendizajes individuales y colectivos. Se llegó así a un predominio de posiciones que se movían en cierto determinismo social en dondelos agentes parecen tener escaso margen de movilidad, innovación o cambio. Sin embargo, desde el alumnado no presencial se plantearon posiciones más dinámicas en donde los cambios sí eran posibles:

M: "Todo el mundo sabe cosas a su manera, dependiendo de dónde te hayas criado.... De la educación que te hayan dado... Aquí porque estamos estudiando lo que estamos estudiando... Pero... a veces ya puedes estudiar lo que sea que lo guían más por lo que dicen los padres [Parece que para esta alumna la educación familiar "no es una salida viable", porque en la familia, "la forma en la que te relacionas con tus padres y hermanos, y cómo ellos lo hacen con los demás hacen que seamos asi", se reproduce la desigualdad social]

$\mathrm{H}$ : "Es que luego oyen joder, "atienden al puto negro y no me atienden a mi". Eso lo oyes y se te queda. Al final la familia hace que veas las cosas de una manera, es tu modelo"

B: "Influye mucho la sociedad. Si yo veo por la calle que pegar es normal... Hay una presión social que terminas haciendo o cogiendo ciertas ideas..."

L [desde casa]: "Estoy de acuerdo, la transformación debe de ser social y no solo individual, tenemos que tener la fe en las nuevas generaciones, en la juventud,

Vivat Academia. Revista de Comunicación. 2022, nº 155, 197-217 
Ralero Rojas, M-I.

De la ocupación al COVID, pasando por los M.E.N.A.S. El diálogo semipresencial como metodología innovadora de aprendizaje antropológico

ofrecerles ayudas e información, impulsar que piensen por sí mismos, y eso se hace desde la educación, programas sociales, culturales, intercambio de información... De la información se nutre el ser humano"

En este punto de la discusión, el grupo presencial alcanza cierta tendencia al determinismo, valorando la dificultad existente en la transformación social basada en las opciones individuales o colectivas; en este momento otras voces (con el rol de observadores en la modalidad presencial) que aún no se habían sumado a la discusión, pidieron hacerlo y plantearon de manera muy breve otros enfoques o miradas en donde intervienen otros actores. Esta intervención propició que participantes que habían llegado aparentemente a posiciones sin salida generaran respuestas diferentes, educativas, emocionales e individuales con las que lo colectivo pudiera verse transformado. De esta forma, las fronteras entre lo individual y lo colectivo se desdibujan, observando que las estructuras de desigualdad también pueden tener relación con las estrategias con las que las personas construyen su propia voluntad de cambio. Desde casa, tras plantear las dificultades existentes para el cambio social siguiendo los cauces educativos, surgió la idea de revolución como única vía real de transformación:

S: "Es que no está solo cerrado a lo que me dice mamá o papá, hay mucha gente ahí influyendo"

T: "¿Qué harías para cambiarlo? Creo que no hay una llave maestra. Es muy complicado una sociedad con... Si yo tengo dos trozos de pollo y X [nombre de alumno que tiene al lado] no tiene ninguno... Cómo hago yo para que cada uno tenga uno y no se acumule la riqueza... Y luego está la voluntad... Si a mi no me interesa esa clase, no la voy a escuchar..."

M [desde casa]: "Individualismo implica práctica individual y eso es una de las consignas del sistema económico que tenemos que verlo como la superestructura donde se enmarca el estado, para cambiar la sociedad, para cambiar la mentalidad no va a ser tan fácil como introducir métodos educativos no individuales porque va a seguir existiendo la práctica abusiva de producción de mercancías, la sociedad consumista, el deseo por enriquecerse a costa de otros, todo ese individualismo no se supera con prácticas reformistas, hay que aplastarlo con la revolución socialista"

Las últimas aportaciones de participantes tanto del grupo presencial como desde fuera (tanto observadores dentro del aula como desde casa) proporcionaron claves importantes para comprender cómo todos esos condicionantes sociales y culturales sin duda operan, pero también observaron el papel de los miembros de una comunidad como algo dinámico y no tan limitado o determinado, donde también sería posible redescubrir esa capacidad de agencia de forma viva, evidenciando ese repertorio cultural existente para utilizar creativamente nuestra propia cultura, donde podemos tener alcance también como respuestas sociales deseables, otras posibles formas de comportarnos y relacionarnos con ese otro sometido a procesos de discriminación: 
Ralero Rojas, M-I.

De la ocupación al COVID, pasando por los M.E.N.A.S. El diálogo semipresencial como metodología innovadora de aprendizaje antropológico

X [desde casa]: "Si, creo que lo que dice es que la información del maestro está condicionada ¿no? Al mismo tiempo que la educación de nuestros padres está condicionada por su educación previa. Pero por eso mismo hay que enseñar a los niños a tener personalidad y un pensamiento crítico, entenderse y entender a los demás, para que puedan superar las condiciones personales del maestro y centrarse en absorber la información sin condicionar"

C: "Hay herramientas que pudieran servir que no interesa que la gente las tenga. Habilidades sociales y educación emocional, por ejemplo. [nota de profesora: el alumno lo plantea como una posible respuesta que no interesa potenciar desde "el estado". Hace un gesto con la mano de desprecio mientras dice "mira toma, ocúltalo"]

$\mathrm{H}$ : "Qué piensan cuando hago esto y qué piensan cuando no lo hago. Sentir eso también educa y hace que te comportes de una forma u otra. Pero eso no quiere decir que no tengas más opciones"

I: "Es que, por ejemplo, eso lo vivimos en el instituto. Cuando yo estaba estudiando, a un chico marroquí le hicieron bullying. Hubo gente que evidentemente se reía. Que lo hicieran los demás, no quiere decir que lo hiciera yo. Depende un poco de los valores y pensamientos que tenga cada uno..."

Finalmente, en la siguiente sesión de clase, se revisaron los discursos y se animó al alumnado que aún no había intervenido a aportar sus propias conclusiones, relacionando estas miradas múltiples de dentro y fuera del aula con las perspectivas EMIC (interna) y ETIC (externa), así como con el carácter holístico de la Antropología en búsqueda de la integralidad; el significado de la/s cultura/s como modelaje pero también desde su uso creativo y cómo desde los márgenes muchas veces se generan importantes cambios sociales; la necesidad de llevar a cabo un ejercicio de extrañamiento para distanciarnos de posiciones etnocéntricas; la relación entre las prácticas sociales y las narrativas (lo hecho y lo dicho); el papel de los prejuicios y estereotipos en los procesos de exclusión, así como el análisis de instituciones como la familia y el peso de otros agentes culturales educativos. La conclusión extraída por el propio grupo sobre esta experiencia fue la de evidenciar cómo a través de la conformación de un grupo con tendencia a la homogeneidad, se habian logrado aportar matizaciones importantes de los temas tratados, alcanzando una mayor profundidad de esta mirada definida por el propio alumnado como social y/o cultural. En las sesiones siguientes de la asignatura, esta base construida entre todas y todos facilitó una mejor comprensión de los sistemas de parentesco, el relativismo cultural y la antropología de las migraciones. En el desarrollo de estos temas, las alusiones del grupo y la profesora a lo expresado y sentido en el grupo de discusión fueron recurrentes. 
De la ocupación al COVID, pasando por los M.E.N.A.S. El diálogo semipresencial como metodología innovadora de aprendizaje antropológico

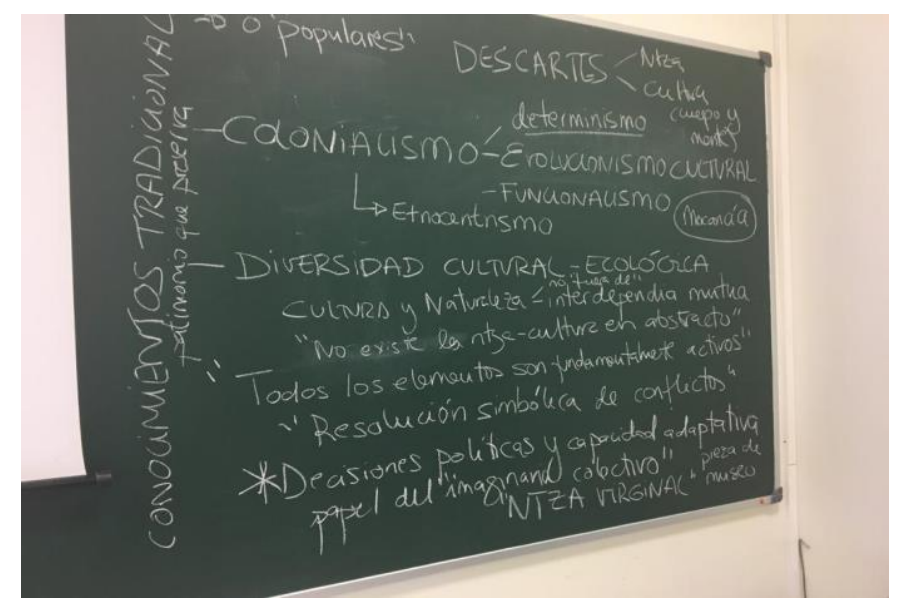

Imagen 4. Extracto en pizarra de conclusiones extraídas del aprendizaje dialógico llevado a cabo en clase.

\section{CONCLUSIONES}

El grupo de discusión presencial mostró una significativa tendencia al acuerdo y al determinismo que se rompió por la participación del alumnado que había asumido desde el aula un rol distante como observador, así como por la introducción de planteamientos diferentes mediante el uso del chat de la plataforma desde casa. Esto nos permitió comprender desde la experiencia vivida la necesidad de afrontar diferentes posiciones y contar con otras miradas a la hora de analizar cualquier fenómeno de la realidad social. Resultó especialmente relevante en este aprendizaje que el alumnado se descubriera portador en sus percepciones y valoraciones de constructos culturales e imaginarios colectivos, mejorando su propia capacidad de distanciamiento y extrañamiento para adentrarse en la comprensión de las realidades descritas. No obstante, es importante advertir que la experiencia que aquí se describe no pretende extraer grandes conclusiones sobre la semipresencialidad (para ello se requeriría de una mayor sistematización de la práctica llevada a cabo de forma contrastada con diferentes grupos), sino poner en relación este nuevo entorno con los objetivos curriculares y transversales de una asignatura que de conlleva una importante carga de reflexividad.

A pesar de tratarse de alumnado de primer curso de Trabajo Social, en una asignatura ubicada además en el primer cuatrimestre, la no directividad del grupo por parte de la profesora no impidió que fueran saliendo discursos y posiciones fundamentales desde dentro de los propios imaginarios para comprender los fenómenos estudiados. A través de la exposición de matices diversos se alcanzó una construcción más amplia y rica del fenómeno de la ocupación, que fue siendo contextualizada mediante el diálogo en otras lógicas de desigualdad y discriminación hacia los otros. La libertad del grupo de discusión para moverse por diferentes temas permitió que se concluyera hablando del papel de la educación dentro de estos procesos de exclusión, permitiendo que las y los participantes modularan sus 
Ralero Rojas, M-I.

De la ocupación al COVID, pasando por los M.E.N.A.S. El diálogo semipresencial como metodología innovadora de aprendizaje antropológico

posiciones asumiendo otras argumentaciones y posibilitando un aprendizaje dialógico rico, diverso y significativo.

En cuanto al alcance de esta investigación, si bien proporciona posibles evidencias sobre el potencial que el aprendizaje dialógico puede tener como herramienta didáctica para el abordaje de temáticas complejas que deben estar sujetas a una fuerte reflexividad por parte de los actores, también se hace necesario constatar su aplicabilidad con una ampliación de las muestras a otros grupos no sectoriales o tan específicos, tanto desde la educación formal como la no formal, más aún si tenemos en cuenta la variable de la semipresencialidad, que nos permitiría en el futuro generar con más facilidad que el entorno presencial espacios de diálogo y reflexividad mixtos entre personas, colectivos, comunidades relevantes para los diferentes temas a tratar. Construir un nuevo conocimiento compartido desde estas herramientas semipresenciales vinculadas con metodologías participativas de investigación-acción puede convertirse en una nueva manera de hacer y repensar la etnografía, tanto dentro como fuera del aula, así como la posibilidad abierta de trabajar en otros entornos posibles para impulsar procesos colectivos de diagnóstico y transformación social. Porque como hemos visto, aquello que aportan las personas o alumnado participante desde fuera puede servir para introducir elementos clave no contemplados por el grupo dialogante presencial.

Por último, concluir que todos los temas que fueron apareciendo a través del grupo de discusión semipresencial sirvieron, al igual que venía ocurriendo con anterioridad con los presenciales, como canalizadores para la introducción dialogada del temario de la asignatura de Antropología, puesto que, como se ha podido evidenciar en la lectura de este trabajo, partiendo de la diversidad de conocimientos previos del alumnado, así como de los propios entornos por donde transita su aprendizaje, la construcción de un nuevo conocimiento compartido se genera de forma más efectiva, coherente y enriquecida bajo modelos que categorizan a dicho alumnado como agentes activos en sus propios procesos educativos y no como meros receptores de contenidos. Ello supone asumir que el papel del alumnado podría equipararse al de los sujetos que construyen la realidad social donde se ubican nuestros objetos-sujetos de estudio, y que desde ese rol se convierten en importantes fuentes de reflexividad para adentrarnos en el análisis de hechos sociales relevantes en el momento actual.

\section{REFERENCIAS}

Alonso, L. E. (1996). “El grupo de discusión en su práctica: memoria social intertextualidad y acción comunicativa". Revista Internacional de Sociología, 13, 536.

Arboleda, L. M. (2008) El grupo de discusión como aproximación metodológica en investigaciones cualitativas, Rev. Fac. Nac. Salud Pública 26(1). Universidad de Antioquía, Colombia, 69-77. https://www.redalyc.org/pdf/120/12026111.pdf 
De la ocupación al COVID, pasando por los M.E.N.A.S. El diálogo semipresencial como metodología innovadora de aprendizaje antropológico

Duque, Elena y Prieto, Oscar (2009). El Aprendizaje Dialógico y sus aportaciones a la Teoría de la Educación. En Revista Electrónica Teoría de la Educación. Educación y Cultura en la Sociedad de la Información, Universidad de Salamanca, 7-30. https://www.redalyc.org/pdf/2010/201014898002.pdf

Greenwood, D. (2000). De la observación a la investigación-acción participativa: una visión crítica de las prácticas antropológicas. Revista de Antropología Social 9, 27-49. https://revistas.ucm.es/index.php/RASO/article/view/RASO0000110027A

Hernández Espinosa, Rafael (2007). Del colonialismo al colaboracionismo dialógicocrítico: una aproximación a la dimensión política y reflexiva de la Antropología en México. Revista de Antropología Iberoamericana 2, 303-322. http://www.aibr.org/antropologia/02v02/articulos/020204.php

Flecha, R. (1997). Compartiendo palabras. Barcelona: Paidós.

Lamela Viera, C. y Vázquez Silva, I. (2013). De la revitalización a la participación. Retos de la antropología urbana ante la "cultura cívica". Zainak. 36, 483-493. https://www.academia.edu/15293487/De_la_revitalizaci\%C3\%B3n_a_la_particip aci\%C3\%B3n_Retos_de_la_antropolog $\%$ C3\%ADa_urbana_ante_la_cultura_c\%C3 \% ADvica

López Francés, Inmaculada. (2010). El grupo de discusión como estrategia metodológica de investigación: aplicación a un caso. Edetania, 38, 147-156.

Montañez Serrano, Manuel. (2010). El grupo de discusión. Cimas Cuadernos. Observatorio Internacional de ciudadanía y medio ambiente sostenible. https://www.redcimas.org/wordpress/wpcontent/uploads/2012/08/m_MMon tanes_ElGRUPO.pdf

Muñoz, Bernardo. (1998). La política social y la participación ciudadana desde la óptica de la Antropología Social. La irreductibilidad de la política. Última Década 9, Cidpa Viña del Mar.

Muñoz, Jonathan (2013). El método dialógico. Una experiencia interdisciplinaria desde la Antropología. En Cuadernos de Antropología 23, 1-26. DOI 10.15517/CAT.V23I1.12834

Porto Pedrosa, L., y Ruiz San Román, J.A. (2014). Los grupos de discusión. En K. Sáenz López, \& G. Támez González, Métodos y técnicas cualitativas y cuantitativas. México: Tirant Humanidades, 253-273. https://eprints.ucm.es/id/eprint/49454/1/2014\%20grupos\%20discusion \%20\%20Porto\%20Ruiz\%20San\%20Roman.pdf 
De la ocupación al COVID, pasando por los M.E.N.A.S. El diálogo semipresencial como metodología innovadora de aprendizaje antropológico

Rodríguez Zoya, L. (2009). Desafíos pedagógicos de la enseñanza de metodología de la investigación: hacia una reconceptualización antropológica del sujeto de aprendizaje.Revista Investigación $\quad$ Educativa 2(2), 105-126. http:// www.scielo.org.bo/scielo.php?script=sci_arttext\&pid=S1997$\underline{40432009000200004 \& \operatorname{lng}=e s \& n r m=\text { iso }}$

Salmerón, H. Rodríguez, S. y Gutiérrez, C. (2010). Metodologías que optimizan la comunicación en entornos de aprendizaje virtual. Revista Comunicar 34 (XVII), 163171. http://dpoi.org/10.3916/C34-2010-03-16 .

Uribe Sánchez, J.L.E (2014). Dialéctica, diatópica y diálogo intercultural. Contribuciones a las Ciencias Sociales, diciembre 2014. https://www.eumed.net/rev/cccss/30/dialectica.html

\section{AUTORA:}

\section{María Isabel Ralero Rojas}

Dra. Antropología Social. Licenciada en Humanidades por la UCLM y en Antropología Social y Cultural por la UCM. Docente en las asignaturas de Antropología en el Grado de Trabajo Social y de Métodos y Técnicas de la Investigación Etnográfica en el Máster de Antropología Aplicada de la UCLM (años 2019-actualidad). Especialista universitaria en Inmigración y Mediación Intercultural con formación y experiencia investigadora en gestión de la diversidad en el ámbito local, intervención comunitaria, construcción colectiva de saberes y coordinación de proyectos de intervención social en barrios de alta diversidad que han supuesto la elaboración de monografías y diagnósticos compartidos territoriales, el trabajo transversal de género, la participación ciudadana e identidades colectivas. Éste último ámbito ha conformado el tema principal de su tesis doctoral. Compagina por lo tanto la docencia universitaria y su tarea investigadora con la Intervención Social Comunitaria a través de la Antropología Aplicada para el impulso de procesos de transformación social. 
Ralero Rojas, M-I.

De la ocupación al COVID, pasando por los M.E.N.A.S. El diálogo semipresencial como metodología innovadora de aprendizaje antropológico

\section{ANEXO 1: Imágenes del chat. Aportaciones desde casa al debate presencial}

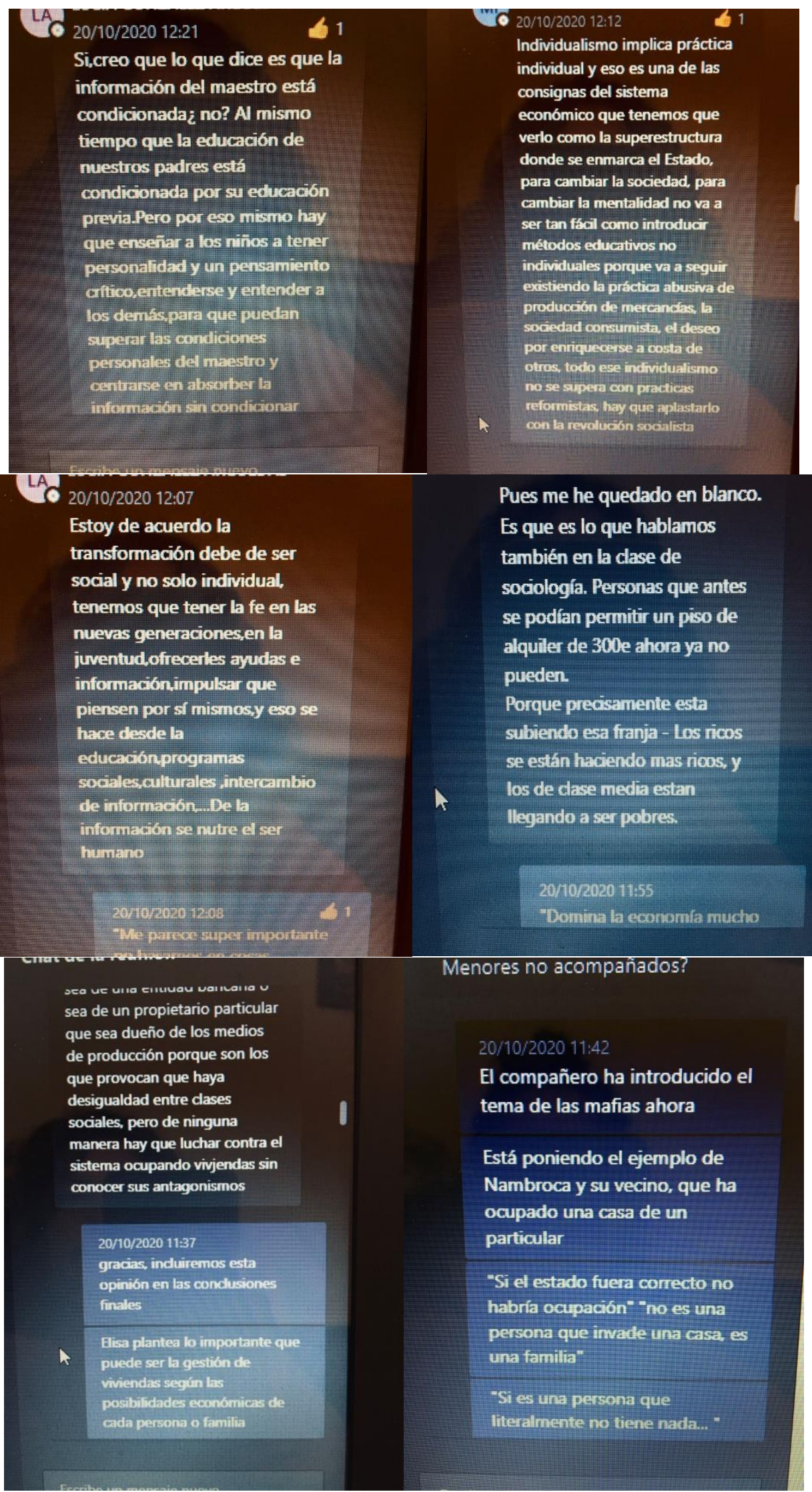

Vivat Academia. Revista de Comunicación. 2022, n 155, 197-217 